\title{
O Conceito de Mediação na Teoria Histórico-Cultural e as Práticas Pedagógicas
}

Maria Aparecida Mello*

\begin{abstract}
RESUMO: Atualmente, a palavra "mediação" tornou-se, de certa forma, comum nas conversas em reuniões pedagógicas e em pesquisas na área da Educação. O termo normalmente é empregado como uma das atribuições de professoras e professores. A mediação nestes casos é interpretada como se fosse uma "ponte" entre a criança e os conteúdos escolares. Mas, será que realmente esse conceito filosófico tem o significado de elo entre dois extremos que de outra forma seria intransponível? O objetivo deste artigo é discutir esse conceito a partir da Teoria Histórico-Cultural, bem como relacioná-lo ao desenvolvimento de aprendizagens escolares e, portanto, sua função nas práticas pedagógicas.
\end{abstract}

PALAVRAS-CHAVE: Mediação. Mediação Pedagógica. Atividade Mediadora. Práticas Pedagógicas. Teoria Histórico-Cultural.

\section{The Concept of Mediation in Cultural-Historical Theory and Pedagogical Practices}

\begin{abstract}
Currently, the word "mediation" has become common in pedagogical meetings, as well as in Education research. This term is usually used as one of the teachers' attributions. Mediation, in these cases, is seen as if it were a "bridge" between the child and the school contents. However, has this philosophical concept really the meaning of linking two extremes that would be insurmountable in another way? Thus, the goal of this paper is to discuss this concept subsidized by Cultural-Historical Theory, as well as connect it to the development of school learning, that is, verify its function in pedagogical practices.
\end{abstract}

KEYWORDS: Mediation. Pedagogical Mediation. Mediated Activity. Pedagogical Practices. Cultural-Historical Theory.

* Prof ${ }^{\text {D }}$ r $^{\text {a }}$ Titular da Universidade Federal de São Carlos, junto ao Departamento de Teorias e Práticas Pedagógicas DTPP/CECH/UFSCar e ao Programa de Pós-Graduação em Educação - PPGE/CECH/UFSCar. Coordenadora do Núcleo de Estudos e Pesquisas sobre a Escola de Vigotsky - NEEVY/UFSCar/CNPq. E-mail: mmello@ufscar.br

\begin{tabular}{|c|c|c|c|c|c|}
\hline APRENDER - Cad. de Filosofia e Psic. da Educação & Vitória da Conquista & Ano XIV & n. 23 & p. 72-89 & jan./jun.2020 \\
\hline
\end{tabular}




\section{Introdução}

A Teoria-Histórico Cultural foi desenvolvida por Liev Semiónovich Vigotsky¹ (1972, 1991,1993, 1995, 1996, 1997, 2001 entre outros), psicólogo russo, que estudou o desenvolvimento das funções psíquicas superiores nos seres humanos. A premissa básica de sua teoria configura-se na afirmação de que os seres humanos são históricos e sociais. Assim cada indivíduo se desenvolve à medida que se relaciona com outros indivíduos, imersos em uma cultura humana.

As funções psíquicas superiores são próprias apenas dos seres humanos e, também, desenvolvemse por intermédio da cultura humana. Tais funções psíquicas superiores proporcionam aos indivíduos o desenvolvimento de habilidades para que se apropriem da cultura humana, diferenciando-os dos animais e, assim, tornando-os efetivamente humanos. Então, as funções psíquicas superiores, segundo Vigotsky (1995), configuram-se em mediadores criados pela humanidade: a linguagem, a escrita, a matemática e o desenho. O desenvolvimento dessas funções é denominado por Vigotsky (1995) de desenvolvimento cultural. Esse processo inicialmente é externo ao indivíduo, no plano social, como função interpsicológica compartilhada entre duas pessoas (a criança e o outro, por exemplo) e, posteriormente, passa a ser interno, no plano psicológico, como função intrapsicológica, no próprio indivíduo. Entretanto, essas funções psíquicas superiores não bastam para que a sociedade humana seja realmente humana. É fundamental que os indivíduos desenvolvam a consciência e o controle de suas próprias condutas em sociedade. Assim, à medida que o desenvolvimento do pensamento avança, por intermédio das funções psíquicas superiores no "processo de domínio dos meios externos do desenvolvimento cultural" [a linguagem, a escrita, a matemática e o desenho] os seres humanos necessitam aprofundar o desenvolvimento das funções psíquicas superiores especiais, denominadas pelo autor de: atenção voluntária, memória lógica, formação de conceitos, entre outras (VIGOTSKY, 1995, p. 29).

Nessa perspectiva, as aprendizagens na Escola de conteúdos que envolvam a linguagem, a escrita, a matemática e o desenho são fundamentais para o desenvolvimento das funções psíquicas superiores das crianças, mas não são suficientes para o desenvolvimento de todas as suas potencialidades para a convivência em uma sociedade mais humana: - é preciso que a Escola potencialize o desenvolvimento dessas funções psíquicas superiores especiais de crianças, jovens e adultos - respeitando suas especificidades. Entretanto, geralmente vemos que a Escola, ao contrário, prioriza o ensino da escrita e matemática, supondo que as funções de abstração, atenção, memória e conceitos serão decorrentes desses conteúdos e, por si só, serão desenvolvidas nos estudantes.

\footnotetext{
${ }^{1}$ A grafia do nome desse autor russo tem várias formas diferentes no ocidente: Vigotski; Vygotski; Vygotsky, Vigotsky. Utilizaremos neste artigo a grafia Vigotsky, uma vez que a letra y em russo tem o som de u, que corresponde à pronúncia desse nome (Vigótscú).
} 
Nesse sentido, nos dias atuais, é fundamental que a função da escola se modifique e, para tanto, será necessária a mudança de concepção sobre cultura dos envolvidos com a educação, uma vez que é a própria cultura a via mediadora do desenvolvimento dos seres humanos.

$\mathrm{Na}$ Teoria Histórico-Cultural, a cultura é definida como o próprio gênero humano, pois o indivíduo, como um ser social, imerso na cultura, aprende e se desenvolve à medida que se apropria (plano intrapsíquico) dessa cultura, por intermédio das relações sociais que estabelece com os outros indivíduos, com os bens culturais produzidos pela humanidade, com os objetos, etc. (plano interpsíquico).

Essa natureza sociocultural dos seres humanos não se superpõe à sua natureza biológica, mas a transforma (VIGOTSKY, 1995). Encontramos na academia interpretações errôneas sobre essa conceituação de cultura na Teoria Histórico-Cultural que reverberam nas práticas pedagógicas e na formação dos futuros professores e professoras. Uma delas é a afirmação de que Vigotsky (1995) não admite as diferenças culturais e nem o aparato biológico dos seres humanos. É importante esclarecermos que nenhuma teoria pode negar o aparato biológico dos seres humanos. O que diferencia a Teoria Histórico-Cultural de outras sobre o desenvolvimento humano é que a vivência em sociedade é determinante para o desenvolvimento dos indivíduos. O aparato biológico apresenta limites para esse desenvolvimento, mas não é desprezado nessa teoria, caminha paralelamente com o desenvolvimento cultural. Outro aspecto importante a ser esclarecido reside no fato de que se a cultura é o produto da vida social e da atividade social dos indivíduos, então, ela terá especificidades diferentes em cada sociedade. Ela não pode ser igual nas diferentes sociedades e nos tempos históricos em relação às formas de convivência entre os seus indivíduos, bem como, em suas manifestações culturais.

Quando a Teoria Histórico-Cultural afirma que a definição de cultura é a própria sociedade humana quer dizer que as diferenças não podem transformar-se em status, privilégios, hierarquização entre as sociedades. Todas as sociedades humanas pertencem ao gênero humano, portanto, todos os seres humanos têm a possibilidade de desenvolver seu pensamento e suas funções psíquicas superiores especiais por intermédio da cultura e da convivência em sociedade. A estigmatização entre sociedades mais desenvolvidas e menos desenvolvidas, assim como, entre diferentes grupos de uma sociedade impedem a compreensão da cultura em si e corroboram para manter ou radicalizar as desigualdades. Todos pertencem ao gênero humano e, portanto, devem ter os mesmos direitos e deveres. Daí a importância do desenvolvimento das funções psíquicas superiores especiais em níveis aprofundados de consciência para que os seres humanos se apropriem da habilidade de autorregulação de sua conduta e, assim, as sociedades possam tornar-se mais humanas.

A Teoria Histórico-Cultural tem vários conceitos-chave que oferecem suporte teórico e metodológico para o conjunto de sua obra. Além disso, tais conceitos podem subsidiar as práticas pedagógicas no desenvolvimento de processos de ensino e de aprendizagem. O conceito de mediação 
está intrinsecamente relacionado aos termos cultura e funções psíquicas superiores especiais dos seres humanos. Iremos discutir tais conceitos a seguir.

\section{O Conceito de Mediação e sua Função nas Práticas Pedagógicas}

O eixo que organiza e gera todos os conceitos da Teoria Histórico-Cultural é o historicismo. Para entendermos o sentido do termo história nessa teoria é fundamental falarmos das "três gerações conceituais produzidas por Vigotsky $(1991,1995)$ a partir do historicismo: a primeira - o tempo humano é história; a segunda - a natureza social do homem - a cultura - e a terceira - o caráter mediatizado da psique humana” (SHUARE, 1990, p. 60).

O "tempo humano é história" refere-se ao processo de desenvolvimento da sociedade humana, tanto na vida individual, quanto social. Na Teoria Histórico-Cultural o processo de maturação orgânica não significa a espera do desenvolvimento, já que a história "ilumina o presente" e nos coloca em dois planos de tempo: "lo que es y lo que fue" para que possamos entender o presente e planejar o futuro. Em termos de práticas pedagógicas, isso significa que o desenvolvimento de aprendizagens ocorre ao mesmo tempo do desenvolvimento humano. Não precisamos esperar a maturação de estruturas internas nas crianças e jovens, tais como, as estruturas fisiológicas, para desenvolvermos o ensino adequado às aprendizagens (VIGOTSKY, 1995, p. 65).

O tempo histórico nos auxilia a olhar as necessidades de aprendizagens dos alunos em função de suas histórias de vida e a planejar formas de ensino que propiciem o desenvolvimento dessas necessidades, bem como a produção de outras.

Os profissionais da Educação, imersos em uma dinâmica cultural, possuem um universo de representações (sobre o mundo, o corpo, a atividade, a profissão, a sociedade, a escola, etc.) que definem e orientam a atividade de trabalho (LEONTIEV, 1978). Essa primeira geração de conceitos da Teoria Histórico-Cultural modifica, portanto, a concepção de ensino, aprendizagem, conhecimento, escola, ser humano, entre outras necessárias para os processos pedagógicos em qualquer etapa do ensino. Os seres humanos, sendo assim, sociais, têm infinitas capacidades de agirem no mundo de forma simbólica em todos os momentos de sua vida, inclusive na atividade profissional que deve estar orientada para a busca de sentido para a sua vida pessoal.

O conceito de tempo histórico nos ajuda a compreender que "el proceso del desarrollo psíquico del hombre es una parte del proceso general del desarrollo histórico de la humanidad" (VIGOTSKY, 1995, p. 62). Assim, os seres humanos ao desenvolverem suas funções psíquicas superiores especiais aceleram o desenvolvimento da humanidade em um determinado tempo.

Daí o imprescindível papel da Escola na priorização do desenvolvimento das funções psíquicas superiores especiais no tempo histórico das sociedades atuais. Se antes a sua função era apenas transmitir os conteúdos produzidos pela humanidade, hoje, em nosso tempo histórico, a função da Escola é 
desenvolver processos mediadores para além de apenas a transmissão dos conteúdos produzidos pela humanidade, cujas informações estão disponíveis em larga escala e de diferentes maneiras pelo avanço da tecnologia. Entretanto, não bastam informações, é necessário saber selecioná-las e compreendê-las criticamente para avanço do conhecimento.

Então, a prioridade da Escola hoje é o desenvolvimento das funções psíquicas superiores especiais em todos e quaisquer seres humanos, de forma que possam desenvolver o pensamento conceitual sobre a sociedade em que vivem, de modo a transformá-la na direção de se tornar melhor e mais humana. Isso modifica imensamente as práticas pedagógicas, uma vez que não basta às crianças, jovens e adultos apenas aprender a ler, escrever, contar, desenhar, mas, especialmente, aprender como compreender os conhecimentos que estão ao seu redor; como agir criticamente, de forma a se beneficiarem destes conhecimentos e, finalmente, como controlar suas condutas nas vivências sociais.

O tempo e a história, consequentemente, nos conduzem a outro conceito fundamental da Teoria Histórico-Cultural - a "atividade". Não é qualquer atividade humana, mas, sim, a consciente e produtiva que desenvolve o psiquismo e transforma os seres humanos. Tal atividade produtiva humana é ampliada pelo uso de ferramentas e, por isso, é diferente de qualquer outro tipo de atividade. Nesse processo de desenvolvimento da atividade produtiva em um tempo histórico, os objetos, por exemplo, criados pelo trabalho humano fazem parte da natureza social dos seres humanos, ou seja, da "cultura", portanto, a segunda geração conceitual. Nas palavras de Vigotsky (1995, p. 34) "la cultura origina formas especiales de conduta, modifica la actividad de las funciones psíquicas, edifica nuevos niveles en el sistema del comportamiento humano en desarrollo".

Dessa forma, o conceito de atividade está intimamente relacionado às funções psíquicas superiores especiais porque é por meio dessa atividade que os seres humanos têm a possibilidade de desenvolverem tais funções que encerram em si a potencialidade de os indivíduos modificarem suas condutas na sociedade, transformando suas condutas orgânicas em culturais (VIGOTSKY, 1995).

Essa mudança de atitude é promovida por intermédio de signos e ferramentas que são criados e se modificam, também, pela cultura. O conceito de signo, na Teoria Histórico-Cultural, refere-se a "todo estímulo condicional creado por el hombre artificialmente y que se utiliza como medio para dominar la conducta propia o ajena”, assim, tais estímulos artificiais têm a função de autoestimulação psicológica que amplia seu significado no que diz respeito ao desenvolvimento do pensamento (VIGOTSKY, 1995, p. 83).

As ferramentas não são apenas objetos com propriedades físicas, mas, também, sociais, pois seu emprego foi elaborado socialmente no desenvolvimento do trabalho coletivo. Por isso, elas se tornam um meio de ação e não basta apenas possuí-las, é necessário dominá-las, como forma de realização do homem. Elas configuram-se em um elemento mediador das atividades dos indivíduos, relacionadas à apropriação do conhecimento. 
Nessa perspectiva, o emprego dos signos e ferramentas como meios auxiliares para o domínio da conduta humana possibilita a atividade produtiva dos seres humanos que os diferencia radicalmente dos animais e amplia, ilimitadamente, sua atividade e sua conduta em sociedade. Ambos possuem a mesma característica principal que é a função mediadora e, também, são subordinados ao conceito de "atividade mediadora" (VIGOTSKY, 1995, p. 93).

Em contrapartida, ambos os conceitos têm diferentes orientações ao exercerem sua função de mediação na atividade mediadora. As ferramentas dirigem-se para fora da atividade, ou seja, elas modificam o objeto da atividade humana, transformando a natureza. Ao contrário, os signos estão orientados para a atividade interna da atividade mediadora. Isso quer dizer que o signo não modifica o objeto porque ele age psicologicamente nos seres humanos; auxiliando-os no processo de autodomínio de suas condutas em sociedade. Portanto, os signos e as ferramentas como parte da atividade mediadora na atividade humana compõem as funções psíquicas superiores e especiais.

Assim, com base na utilização das ferramentas que pressupõem o desenvolvimento dos órgãos e funções específicas do ser humano, a inserção das crianças na cultura, ainda, vem sendo determinada por uma concepção de desenvolvimento humano apenas biológica, na qual é imprescindível a maturação dos aparatos biológicos e funções correspondentes para as aprendizagens.

É comum nos depararmos com análises de professores sobre a conduta dos alunos por analogia ao desenvolvimento orgânico do corpo humano, como um processo totalmente natural e biológico. Os aspectos históricos e da cultura ficam à margem ou servem para justificar a falta de intervenções, como se nada que fizessem fosse adiantar. Este tipo de procedimento de ensino está pautado em uma concepção de desenvolvimento puramente orgânico, na qual os aspectos culturais são deixados à margem, ou se levados em consideração, sofrem do mesmo tipo de análise, ou seja, secundarizando os aspectos culturais em função de concepções biológicas e inatas.

Contudo, as análises pormenorizadas do processo de aprendizagem de utilização das ferramentas, por exemplo, pela criança, em uma perspectiva mais abrangente de desenvolvimento humano que envolve as relações sociais da criança com outras crianças, adultos, objetos, espaços e outros mediadores sociais, demonstram que a cultura assume preponderância e modifica o desenvolvimento orgânico por intermédio da atividade mediadora. Assim, esse processo de transformação dos seres humanos ao conviverem em sociedade caracteriza o "desenvolvimento cultural” (VIGOTSKY, 1995) que vai além dos processos de crescimento, maturação orgânica nos seres humanos, pois envolvem, necessariamente, os conceitos de história, tempo, cultura, atividade, funções psíquicas superiores e especiais, ferramenta e signo, entre outros dessa abordagem teórica.

Ao estudar as funções psíquicas superiores, Vigotsky (1995, p. 39) demonstrou que, no processo de desenvolvimento cultural, cada uma das funções psíquicas ultrapassa os limites do sistema da atividade orgânica e inicia seu desenvolvimento cultural em um sistema de atividade completamente novo. “Ambos os sistemas se fundem formando um entrelaçamento de dois processos genéticos [gênese], mas 
essencialmente diferentes". O autor afirma que o desenvolvimento cultural adquire um caráter muito peculiar que não pode comparar-se com nenhum outro tipo de desenvolvimento, citando o desenvolvimento da linguagem na criança, como a fusão desses dois planos de desenvolvimento: o orgânico e o cultural.

Nas práticas pedagógicas em creches, especialmente, na etapa de Educação Infantil, a linguagem da criança avança na medida em que ela interage com as professoras, objetos, outras crianças, diferentes espaços, os quais são mediadores importantes nessa etapa de desenvolvimento cultural.

A compreensão do conceito de desenvolvimento cultural da criança nessa abordagem teórica perpassa, fundamentalmente, pelo entendimento dos resultados das investigações de Vigotsky (1995) demonstrados no início do século XX, os quais continuam muito atuais. Tais resultados de suas pesquisas demonstraram que o desenvolvimento humano se revela sob rupturas e avanços por saltos, se contrapondo à concepção equivocada, vigente na época que persiste até hoje, de desenvolvimento como um caminho reto e contínuo. Assim, as aprendizagens na Escola concebidas, ainda, como um desenvolvimento linear, com etapas seguidas umas após as outras parece ir na contramão do desenvolvimento cultural humano e das sociedades. Um exemplo disso são as crianças de 0 a 6 anos hoje. Se na Educação Infantil a concepção de criança permanece relacionada apenas à sua idade biológica e não ao seu desenvolvimento, ou seja, ao que ela já sabe e tem a possibilidade de aprender, a aprendizagem e o desenvolvimento ficam limitados apenas ao que as crianças da mesma idade faziam antigamente. A criança real fica invisível aos olhos dos envolvidos na sua educação escolar. Isso gera na criança desmotivação da atividade, irritabilidade, entre outros comportamentos já conhecidos por professoras e gestores, tornando-a difícil de educar.

Além disso, nos processos de aprendizagem e de desenvolvimento humano existem momentos cruciais próprios de cada indivíduo que estão relacionados a uma série de outros momentos anteriores e posteriores de sua vivência em sociedade. Apesar de esses processos de aprendizagem e desenvolvimento estarem intrinsecamente imbricados, apresentam complexas relações internas e não coincidem, necessariamente, à estrutura da Escola e à forma com que ela organiza o ensino de seus componentes curriculares. Tomemos por exemplo, os problemas relacionados a não alfabetização de crianças. O tempo para o domínio da aprendizagem desses conteúdos pela criança, estipulados pelos currículos escolares, não é o mesmo que, geralmente, as crianças necessitam para a tomada de consciência interna da linguagem e o domínio da leitura e da escrita (MELLO, 2007).

O descompasso entre os processos de aprendizagem escolar e o desenvolvimento é a consequência da fragilidade de relações intencionais entre as necessidades de aprendizagens das crianças, jovens e adultos e a necessária atividade mediadora consciente dos profissionais da Escola para o desenvolvimento das funções psíquicas superiores e especiais dos estudantes. Isso porque as relações intencionais devem ser recíprocas, ou seja, o estudante precisa desenvolver a intencionalidade sobre sua necessidade de aprender, ao mesmo tempo em que os professores precisam ampliar profundamente suas 
intencionalidades na proposição de atividades mediadoras. Essa fragilidade de intenções produz o referido descompasso que, por sua vez, gera nos alunos o fracasso que, certamente não é deles, mas, sim, da ineficiência da Escola em mudar e avançar sua concepção de ensino, aluno, aprendizagem e desenvolvimento humano.

Petrovsky (1980) explica que a intencionalidade se caracteriza como uma forma especial dos seres humanos regularem as suas condutas, refrearem seus impulsos e aspirações, uma vez que se relaciona com o desenvolvimento das funções psíquicas superiores especiais. A atividade humana necessita da organização consciente de sequências de ações diferentes e coerentes com os fins estabelecidos, também de maneira consciente.

A Escola insiste em manter-se na concepção em que a criança, o jovem e o adulto em si não são concebidos como prioridade, mas, sim, os conteúdos que, geralmente, são desconexos das vivências dos estudantes e da própria função desses conteúdos para o avanço do conhecimento. A Escola ao longo do tempo passa a ser um lugar desmotivador para a aquisição do conhecimento.

A Teoria Histórico-Cultural, ao discutir sobre a imprescindibilidade do desenvolvimento das funções psíquicas superiores e especiais por intermédio da atividade mediadora na Escola, auxilia os professores e gestores a compreenderem esse descompasso entre os processos de aprendizagem e desenvolvimento. Ela argumenta que a coincidência de uma ou outra fase ou forma de desenvolvimento orgânico gerou ao longo do tempo tal entrelaçamento entre ambos os processos - orgânico e cultural que impediu a diferenciação de um processo do outro e se confirmou de que o domínio das formas culturais da conduta humana era apenas um sintoma de maturação orgânica, observável por meio das mudanças corporais. Esses sintomas são confundidos com o próprio conteúdo do desenvolvimento humano, principalmente na Escola em que essa concepção tem grande aderência; mas não são excludentes de outras instituições da sociedade tais como, as famílias. Um exemplo que denota essa concepção e seu descompasso dos avanços do conhecimento está no que diz respeito ao atraso no desenvolvimento da linguagem do bebê ou à impossibilidade de dominar a linguagem escrita em uma idade específica que são diagnosticados precocemente como sintomas de atraso mental (VIGOTSKY, 1995). A história de vida, o tempo e o tipo de atividade são desconsiderados neste diagnóstico.

Contudo, a mudança de concepção dos envolvidos com a educação também envolve a intencionalidade em ir à busca das soluções para os problemas de ensino e de aprendizagem. Para tanto, não basta falar em atividade mediadora sem compreender o conceito de mediação.

Leontiev (1978, p. 80), um dos pesquisadores da Escola de Vigotsky, para explicar a importância da mediação no desenvolvimento humano, remete-se à atividade, especificamente humana, chamada "trabalho". O trabalho é caracterizado por dois elementos interdependentes: o primeiro, a produção e utilização de instrumentos e, o segundo, a realização coletiva dessa atividade. Dessa forma, no trabalho, os seres humanos relacionam-se com seus pares. "O trabalho, é, portanto, desde a origem mediatizado simultaneamente pelo instrumento e pela sociedade". É uma atividade, originariamente, social, baseada 
na cooperação entre as pessoas e que mediatiza a comunicação entre elas. Então, os seres humanos criaram o trabalho e os instrumentos necessários que exercem a mediação entre o indivíduo e o objeto de sua atividade de trabalho. Leontiev (1978) afirma, assim, que o traço fundamental da atividade humana é seu caráter mediatizado pelo instrumento, criado na própria atividade de trabalho.

O processo de avanço da atividade de trabalho ao longo do desenvolvimento das sociedades proporcionou também o desenvolvimento humano, já que os seres humanos se apropriam ou não dos conhecimentos produzidos pela humanidade pela via das mediações, as quais podem ser infinitas. As mediações, portanto, podem ajudar os indivíduos a se desenvolverem como, também, podem deixá-los permanecer em níveis cômodos de desenvolvimento. Então, não são quaisquer mediações ou mediadores que impulsionam o desenvolvimento do psiquismo humano. É preciso para isso um nível de intencionalidade muito aprofundado de atividade mediadora para transformar o desenvolvimento cultural humano. A atividade mediadora deve modificar-se e aprofundar-se à medida que os indivíduos criam novas necessidades de aprendizagens para si e, portanto, de se desenvolverem. Se não há necessidade de mudar, a acomodação é a primeira opção.

Nesse processo, o desenvolvimento das funções psíquicas superiores e especiais exercem papel preponderante. Daí a necessidade de a Escola compreender e investir no desenvolvimento delas nas atividades que propõe aos estudantes, criando neles a necessidade da busca do conhecimento em detrimento da cristalização de vivências no seu interior.

Se o foco da Escola for o desenvolvimento das funções psíquicas superiores especiais de atenção voluntária, memória voluntária, pensamento teórico, desenvolvimento de conceitos por intermédios dos conteúdos escolares com base na criação de necessidades de aprendizagens dos estudantes, então, ela objetiva sua função social.

Nossa intenção não é desconsiderar tudo o que a Escola vem produzindo ao longo da história humana, pelo contrário, pretendemos aqui potencializar seu papel nessa história de forma que os seres humanos se apropriem de sua humanidade. As atividades mediadoras exercem papel preponderante nesse processo, uma vez que são vias de mão dupla de aprendizagem: beneficiam tanto quem as engendram (profissionais) como o sujeito delas (o aluno).

$\mathrm{Na}$ direção de expandir o papel da Escola, a Educação Básica criaria e recriaria seus significados para a sociedade. Na etapa de Educação Infantil, por exemplo, a educação, cuidado e assistência nunca seriam concebidas de maneira dicotômica ou pejorativa, uma vez que o foco seriam os bebês e as crianças perante suas necessidades de aprendizagens. As rotinas diárias seriam reelaboradas continuamente para satisfazer essas necessidades de aprendizagens, bem como, criariam outras para além das aprendizagens já apropriadas pelas crianças.

A mediação do pensamento torna possível aos indivíduos estabelecerem relações, interações, comparações, percepções e pensar abstratamente, dispensando a necessidade de ver determinados fatos 
para acreditar nas suas existências. Portanto, o pensamento é o "processo de reflexo consciente da realidade" (LEONTIEV, 1978, p. 84, grifo nosso).

À medida que a consciência dos seres humanos se eleva, novas mediações são exigidas em função da satisfação e criação de suas novas necessidades que fazem com que desenvolvam, também, novas habilidades na direção de transformar a realidade na qual vivem. Esse processo envolve, necessariamente, atividades mediadoras cada vez mais intencionais, bem como, necessidades mais intencionais.

$\mathrm{Na}$ Escola, quando o professor decide propor uma determinada atividade para os estudantes, pressupomos que ele conheça as necessidades dos alunos. Nesse processo de escolha da atividade necessária para os estudantes se confrontam motivos, intenções e ações subsidiados por suas concepções e pela compreensão de seu papel no desenvolvimento de aprendizagens dos estudantes. A ações intencionais geram inquietude, tensões e incômodo frequentes a esse professor porque, ao mesmo tempo em que ele precisa dominar o conteúdo de ensino com base nas necessidades dos estudantes, isso, também, gera nele outras necessidades de aprofundar seus conhecimentos. Esse processo de relações com o conhecimento, com os outros e com diferentes tipos de instrumentos mediadores chamamos de mediação pedagógica. Por isso, não podemos banalizar esse conceito, atribuindo-o a toda e qualquer prática pedagógica que não se insere nesse processo de intencionalidade e consciência aprofundadas.

A mediação pedagógica corre o risco de não ser eficaz às aprendizagens e, pior, impedi-las, se não for exercida nesse processo de completa consciência e intencionalidade do fim a atingir. Além disso, cada situação antes, durante e após a mediação pedagógica é nova, uma vez que os alunos não são os mesmos, não têm as mesmas experiências e vivências sobre aquele assunto. Isso demanda do professor atitudes de disponibilidade em compreender cada situação em si que, associadas ao instrumentos mediadores e ao domínio dos conteúdos de ensino possam auxiliá-lo a analisar com clareza cada uma delas, de modo a reorganizar a atividade na situação em análise e propor novas atividades mediadas intencionais aos estudantes em direção à aprendizagem.

Então, para exercer a mediação pedagógica de acordo com o papel da Escola hoje, em direção ao desenvolvimento das funções psíquicas superiores especiais, são necessários cinco elementos principais. O primeiro deles é o professor ter a clarez̧a sobre suas concepçõos de ensino, aprendizagem, estudante, escola, conhecimento, entre outras que envolvem sua prática pedagógica; e, ainda, se elas estão pautadas na cultura como fator preponderante de desenvolvimento humano. O segundo é a compreensão de que as relações entre ele, os estudantes e os instrumentos pedagógicos, ou não, são fontes de aprendizagens necessárias, tanto para os estudantes, quanto para ele próprio. O terceiro configura-se nos conteúdos escolares que devem ser adequados às necessidades de aprendizagens dos estudantes e, portanto, não se resumem a língua portuguesa e matemática, mas estão em constante mudança, uma vez que a sociedade está em movimento e ela é quem atribui o significado dos conteúdos que precisam ser trabalhados na Escola, mesmo que esta não os reconheça. O quarto é o domínio desses conteúdos pelo professor. E o quinto e último, mas não menos importante, é a busca constante de instrumentos mediadores necessários para propor atividades mediadoras para 
o desenvolvimento das aprendizagens dos estudantes, uma vez que essa busca contínua auxilia o professor a realmente dominar os conteúdos a serem ensinados.

Com base nessa argumentação, o conceito de mediação não pode ser interpretado na Escola como se fosse uma ponte entre o conhecimento e os estudantes ou, ainda, conceber o professor como o único mediador. Ele é o principal, uma vez que, por intermédio dele, outros mediadores devem ser utilizados em atividades mediadoras, a fim do desenvolvimento das aprendizagens dos estudantes. Em contrapartida, a mediação é uma atitude constante no trabalho do professor, mas se ela estiver dirigida à reprodução de atitudes passivas, à concordância de pensamentos, aos conteúdos que pressupõem verdades imutáveis, ela não está direcionada ao desenvolvimento do pensamento, mas ao seu adestramento.

Assim, para que a mediação pedagógica efetivamente avance o desenvolvimento das aprendizagens escolares é preciso também que haja a formação dos professores para exercer seu papel de mediador principal. Entretanto, as formações iniciais e continuadas ainda estão pautadas em discutir conteúdos fixos e não concepções e possibilidades de mudanças em função das exigências deste tempo.

As pesquisas em educação que envolvem as práticas pedagógicas também têm seu papel inadequado, pois, ainda estão centradas nas mesmas questões sobre a formação de professores, como por exemplo, o que pensam sobre determinado conteúdo ou como fazem determinada atividade. Essas pesquisas, geralmente, estão subsidiadas por instrumentos metodológicos que se resumem a questionários, entrevistas ou, no máximo, ações de formação continuada com conteúdos préestabelecidos.

Outro aspecto dessa problemática são as atitudes de obviedade frente ao conhecimento produzido cientificamente que, muitas vezes, estão presentes nos envolvidos com a educação escolar básica, bem como com o ensino superior, uma vez que elas são empecilhos às ações intencionais, porque o óbvio está consolidado e não há espaço para a dúvida, a crítica, a transformação.

Vigotsky (1991, p. 242) discute que o professor deve saber o que a criança já aprendeu e delinear o que ela necessita aprender no final do processo de aprendizagem:

Devemos determinar siempre el umbral inferior de la instrucción. Pero la cosa no acaba ahí: devemos saber estabelecer el umbral superior de la instrucción. Sólo dentro de los límites existente entre estos dos umbrales puede resultar fructífera la instrucción. Sólo entre ellos está encerrado el período óptimo de enseñanza de la matéria en cuestión. La enseñanza debe orientarse no al ayer, sino al mañana del desarrollo infantil (grifo do autor) (VIGOTSKY,1991, p. 242).

Então, fazer avaliações diagnósticas sobre o que os estudantes já sabem sobre o assunto e identificar onde é necessário avançar é o que Vigotsky (1995) denominou de zona de desenvolvimento proximal. Esse conceito é imprescindível para a implementação de mediações pedagógicas, bem como para propor atividades mediadoras, cujos mediadores foram escolhidos e/ou produzidos cuidadosamente 
pelo professor, os quais terão o papel de ajudar os estudantes a aprenderem aquilo que eles ainda não conseguiram se apropriar totalmente. Assim, a zona de desenvolvimento proximal é tudo o que a criança, o jovem ou o adulto pode aprender com ajuda, colaboração, mediação. O que eles já sabem, que foram identificados nas avaliações diagnósticas foi denominado por Vigotsky (1995) de nível de desenvolvimento atual.

Assim, nessa teoria, o desenvolvimento humano tem dois momentos importantes: a zona de desenvolvimento proximal, na qual residem as possibilidades de aprendizagens e apenas um nível, que é aquilo que já é conhecido, já foi aprendido. Esses dois momentos caminham paralelos durante a vida toda dos seres humanos, portanto, não são considerados como dois níveis justapostos, nem duas fases ou períodos seguidos. Quando a criança é pequena, tudo ao seu redor torna-se necessidades de conhecimento. Ela está aberta para essas aprendizagens e fornece muitos indícios sobre o que necessita aprender para compreender as relações ao seu redor. Essa situação faz com que esses dois momentos de desenvolvimento sejam mais visíveis para a professora que trabalha com mediação pedagógica planejada para essas necessidades de aprendizagens.

À medida que essa criança cresce, tornando-se jovem e adulta, esses dois momentos não são tão visíveis e a mediação pedagógica deve ampliar-se para outros tipos de instrumentos mediadores que envolvem tanto a criatividade do professor, mas, principalmente a dos estudantes. Essa situação é diferente porque o essencial nestas etapas de desenvolvimento humano é que ocorra o autocontrole das necessidades de aprendizagens, a partir do incremento da autonomia e das vivências sociais. Entretanto, os professores continuam tendo papel principal na mediação pedagógica.

$\mathrm{Na}$ escola sempre haverá necessidade de mediação pedagógica intencional, em qualquer etapa ou nível de ensino. Entretanto, as ajudas na zona de desenvolvimento proximal vão se tornando menos frequentes, porém mais complexas, uma vez que os motivos para aprender, também, se transformam em razão das vivências e necessidades dos estudantes. Nessas etapas a complexidade da mediação pedagógica revela-se na necessidade de potencialização do desenvolvimento da habilidade de ir à busca do conhecimento pelos próprios estudantes, ao mesmo tempo, em que o professor continua na busca dos mediadores potentes para isso. As atividades mediadoras propostas pelo professor passam a exigir dos estudantes o desenvolvimento de atividades volitivas.

Petrovsky (1980) discute a atividade volitiva como fundamental para o desenvolvimento humano, uma vez que ela auxilia os indivíduos na autorregulação de suas condutas, dificultando o aparecimento de atos em desacordo com suas convicções, ideais, valores. A autorregulação da conduta está intrinsecamente relacionada à intencionalidade, uma vez que, ao dirigir a atividade para um objetivo específico, os indivíduos concentram suas energias nessas ações. As atividades volitivas, então, auxiliam os estudantes a permanecerem no objetivo, mesmo que não seja prazeroso.

A mediação pedagógica, para tanto, precisa envolver, principalmente, a problematização e a discussão de hipóteses sobre o conhecimento em questão, em todos os níveis de ensino, relacionando-o 
à vida dos estudantes. Essa afirmação parece óbvia, mas ela não acontece se o próprio professor não desenvolver a autonomia e habilidades volitivas. Em contrapartida, o cotidiano escolar precisa estar estruturado de maneira que favoreça o desenvolvimento da autonomia de todos os envolvidos na Escola.

A mediação pedagógica necessária para o desenvolvimento das aprendizagens dos estudantes torna-se efetiva em relação à autonomia de ambos. Se o professor necessita utilizar um potente mediador que a escola não tem ou não concebe como tal, sua autonomia profissional será colocada à prova, a partir de sua clareza sobre a imprescindibilidade do instrumento e de sua argumentação para adquiri-lo e/ou utilizá-lo.

As atividades de mediação pedagógica por intermédio da problematização e elaboração de hipóteses envolvem reflexão, discussão crítica entre os grupos de estudantes e realização de pesquisas. $\mathrm{Na}$ medida em que os estudantes desenvolvem a percepção sobre as possibilidades de como fazer algo e os caminhos para as soluções, eles atribuem motivos, significado e sentido para aprender, aprofundam a intencionalidade para o estudo e desenvolvem a consciência sobre o assunto, relacionando-o ao mundo em que vivem.

Outros aspectos da mediação pedagógica envolvem a necessidade de orientação, discussão de conceitos subjacentes ao assunto sob diferentes pontos de vista, bem como, trabalhar esses conceitos com base no desenvolvimento científico, quebrando preconceitos e cristalizações deles já existentes nos alunos e, principalmente, disponibilizar instrumentos teórico-práticos em todas as atividades propostas como mediadores potenciais de aprendizagens.

Uma importante e imprescindível habilidade a ser desenvolvida pelo professor para exercer a mediação pedagógica é a observação. O aprofundamento dessa habilidade torna-lhe visível as necessidades de aprendizagens dos alunos e juntamente com o necessário domínio dos conteúdos ilumina os possíveis caminhos para a elaboração e/ou escolha dos instrumentos mediadores que envolverão a mediação pedagógica.

Para o desenvolvimento da observação, o professor necessita desfocar seu olhar das aprendizagens dos conteúdos escolares em si e ampliá-lo para o desempenho dos alunos durante a atividade, tendo como base os conceitos de zona de desenvolvimento proximal e nível de desenvolvimento atual, ou seja, o que o aluno já sabe ao fazer a atividade com facilidade e o que ele precisa ainda desenvolver com ajuda de outros mediadores em outras atividades mediadoras. Durante esse processo de observação focalizada no desempenho dos alunos, o professor precisa identificar as relações entre o desenvolvimento da atividade e os mediadores que escolheu para que os alunos possam se apropriar do conteúdo. Essa avaliação lhe fornecerá as bases para a elaboração das próximas atividades mediadoras.

Portanto, esse processo envolve não apenas a avaliação do aluno em relação à aprendizagem do conteúdo específico, mas, principalmente, se os mediadores escolhidos pelo professor estão sendo efetivos; se há necessidade de modificá-los ou de rearranjá-los. 
$\mathrm{Na}$ etapa de Educação Infantil, por exemplo, é comum as crianças brincarem no parque sem a interferência da professora. É exatamente nesses momentos que a professora deve apurar sua habilidade de observação e avaliar os mediadores que estão disponíveis para as crianças brincarem. Estar perto delas, ouvir o que conversam em suas brincadeiras, como se relacionam com os objetos, quais conceitos estão em desenvolvimento nas suas linguagens, entre outras situações, são ações que auxiliam a professora a preparar suas atividades em outros ambientes, a partir dos conteúdos que as crianças necessitam aprender naquele momento.

Em uma atividade de formação continuada com professoras de Educação Infantil, a partir de metodologia colaborativa na perspectiva da Teoria Histórico-Cultural, Mello; Campos (2008) discutiram com as professoras a importância da atividade de observação e, principalmente, como a reflexão sobre a interpretação da situação observada pode indicar as concepções que estão subjacentes às suas práticas pedagógicas. Uma das estratégias que utilizaram para potencializar o diálogo sobre essas práticas pedagógicas foi a solicitação às professoras que observassem algumas brincadeiras das crianças e registrassem suas impressões. Os autores apresentam um exemplo de descompasso entre o que a professora espera de desempenho das crianças e a sua dificuldade de interpretação sobre esse desempenho.

Era uma turma de crianças de 3 anos de idade, estavam brincando de casinha duas meninas. Uma delas representava o papel de mãe e a outra de filha. A filha chamava a mãe que respondia: _ "Não posso estou lavando roupa". (MELLO; CAMPOS (2008, p. 299)

Mello; Campos (2008) relatam que essa professora verbalizou, inicialmente, que a tarefa de observar as crianças brincando lhe deu uma outra visão sobre as crianças para as quais ela ensinava e, em seguida, que ficou muito surpresa com o tema da brincadeira dessas crianças, pois esperava que ao deixálas brincar sem a sua interferência, fossem dramatizar a história de príncipes e princesas que ela havia lhes contado minutos antes. Não imaginava que as crianças pudessem brincar com temas reais e, não compreendia o fato de não dramatizarem a história de conto de fadas, já que as crianças haviam gostado muito da história contada.

Apesar de este estudo ter sido realizado em 2008 os resultados que ele apresenta estão, ainda, muito atuais e estão relacionados ao papel da mediação pedagógica que não se resume apenas em disponibilizar os instrumentos mediadores de aprendizagens, mas, principalmente, como avaliá-los e modificá-los, a partir das necessidades de aprendizagens das crianças. E, além disso, que é preciso conhecer essas necessidades das crianças para que a mediação pedagógica possa ser condizente com elas.

O estudo aponta também que a efetividade da mediação pedagógica vai ao encontro da imprescindibilidade de superação das concepções romantizadas de criança que estão direcionando as práticas educativas, principalmente, nos dias atuais. Por outro lado, nos demais níveis de ensino, as concepções preconceituosas, cristalizadas sobre aluno, também são mediadores importantes para o 
desenvolvimento da mediação pedagógica, mas atrapalham a sua efetividade nas aprendizagens dos estudantes.

O confronto das concepções dos professores com o resultado das observações dos alunos durante as atividades pode gerar inquietações nesses profissionais, uma vez que a criança, o jovem e o adulto que se apresentam podem ser muito diferentes do imaginado. Entretanto, ele é imprescindível para a transformação das práticas pedagógicas e para as aprendizagens dos estudantes.

Leontiev (1978) argumenta que a relação entre os motivos e a evolução das necessidades humanas consiste na ampliação de objetivos mais amplos para as ações que compõem as atividades escolares que não correspondam diretamente apenas à satisfação das necessidades de aprendizagem dos alunos, mas para a criação de novas necessidades. Isso significa que o professor passa a direcionar os motivos de suas ações a um fim, intencional, transformando suas ações em atividades. Essas atividades são especiais, pois exigem atos que reflitam a relação entre o motivo de uma atividade escolar específica e o de uma atividade escolar muito mais ampla, a qual gera uma relação vital, maior e mais geral do que aquela atividade específica em questão.

Nessa perspectiva, não basta apenas aprender a ler e escrever, mas desenvolver as funções psíquicas superiores especiais de maneira que a leitura e a escrita possam ser atividades mediadoras potentes de desenvolvimento daquele aluno que, por meio delas, produz e elabora, criativamente, atividades mediadoras que possam melhorar sua vivência em sociedade, porém não somente a sua, mas sim dos que se relacionam com ele. Esse é o processo de transformação para uma sociedade mais humana. Cada indivíduo utilizando seu potencial de inteligência, de intencionalidade, de consciência e de autocontrole sobre suas atitudes para o coletivo e não apenas para si.

Uma particularidade importante da atividade volitiva, segundo Petrovsky (1980), é a consciência de liberdade que ela gera na pessoa. O fato de poder agir de uma maneira e não de outra estabelecida por alguém, sem a presença da costumeira insegurança pela falta de princípios e estratégias que direcionem a sua decisão, desenvolve na pessoa a sensação de liberdade e de responsabilidade pelos seus atos, tornando-a sujeito da própria ação.

O desenvolvimento das funções psíquicas superiores especiais que envolvem a atividade volitiva exige a compreensão do fim desejável - o fato deste fim ser realizável, pois as pessoas podem desejar coisas que não têm como se concretizar, pelo menos naquele momento e daquela forma. A etapa essencial da ação volitiva é a reflexão e planejamento de como atingir o fim proposto, ou seja, o delineamento das estratégias para realizá-lo e os tipos de ações necessárias para isso (PETROVSKY, 1980).

A tomada de decisão não é um processo simples, pois por intermédio dela se determina a base pela qual se vai desenvolver a ação volitiva. Tomar decisões implica se apropriar de conhecimentos que possam direcionar os possíveis modos de ação e a sua efetividade, comparada às tentativas já realizadas por outras pessoas em situações similares. 
Em resumo, portanto, a mediação pedagógica que a Teoria Histórico-Cultural preconiza não é simplesmente entrar em uma sala de aula, em qualquer nível de ensino e transmitir conteúdos especificamente escolares. Ela é mais complexa que essas ações juntas, porém não é difícil e nem impossível ao professor. O professor é o principal mediador nesse processo porque é ele quem escolhe, elabora, produz os mediadores potentes para as aprendizagens dos estudantes.

Esses mediadores, geralmente, não precisam ser, necessariamente, produzidos e nem estão distantes do professor. Assim como os signos, a linguagem, os objetos, a relação com os adultos e com outras crianças são importantes mediadores no processo de aprendizagem e desenvolvimento dos estudantes, o espaço físico, organizado de maneira intencional para a realização das atividades mediadoras, também pode contribuir de maneira significativa nesse processo.

A escola, geralmente, não se configura em um espaço socialmente organizado para o desenvolvimento das aprendizagens de crianças, jovens e adultos. A organização dos seus espaços é realizada normalmente em função da contenção de movimentos e de interações, restringindo as inúmeras e possíveis mediações, qualitativamente diferentes, se esse espaço fosse organizado e pensado nas possibilidades de aprendizagens dos estudantes. Seus espaços físicos internos e externos compõem parte significativa dos processos de ensino e aprendizagem que devem ocorrer nela. O ambiente que está envolto em um espaço determinado tem valor simbólico para os indivíduos que utilizam esse espaço e se esse valor simbólico é carregado de significações que por meio de signos regulam e transformam as atitudes desses indivíduos, então esse espaço tem intencionalidade. Ao ser constituído e/ou organizado por alguém, sempre há subjacente a ele, uma intenção e isso precisa ser levado em consideração.

Nesse aspecto a observação apurada e intencional do professor é o seu instrumento primordial. Além disso, as crianças, jovens e adultos precisam ser ouvidas em relação a esses espaços e sua organização porque eles têm o que falar. Essas visões sobre o espaço e a observação das atividades neles auxiliam o professor a modificar sua organização para potencializar as aprendizagens.

A disposição usual das carteiras nas escolas, em fileiras todas de frente para a lousa, sugere que o foco das aprendizagens são os conteúdos e o professor, em detrimento das relações entre os estudantes, com o professor, com o espaço e com os conteúdos. Espaços organizados desse modo limitam o movimento, que quase sempre é um mediador necessário para a manutenção da atenção no conteúdo; além de dificultar a observação do professor sobre os elementos mediadores que escolheu e sobre as necessidades de aprendizagens dos estudantes. Vigotsky (1995) afirma que quando são impostas limitações físicas e culturais ao desenvolvimento da criança (nesse caso), estas se transformam em um obstáculo para as suas aprendizagens.

Outras vezes os espaços são utilizados pelo professor como estratégia de chamar a atenção dos estudantes, mas a atividade proposta nele não focaliza as suas aprendizagens, mas a disciplina e ordem por intermédio de regras já determinadas. 
Sitta e Mello (2015) relatam que em uma escola de Educação Infantil uma professora utilizou o espaço externo da escola que era arborizado e amplo para desenvolver atividades com as crianças. Entretanto, ela divide a classe em dois grupos, um grupo faz a atividade e o outro fica sentado olhando. Dessa forma, a observação é direcionada pelo medo da aula ficar tumultuada e o professor perder o controle, pois o movimento normalmente é interpretado como bagunça. A mediação pedagógica nesses casos está atuando de maneira mais negativa do que positiva.

Em contrapartida, a escola pode ter ótimas condições e infraestrutura nos seus diferentes espaços, mas se o professor não pensa sobre eles como potenciais mediadores para as atividades que ele planeja, eles serão apenas parte da estrutura física.

Lima (1989) já dizia que: "não há espaço vazio, nem de matéria nem de significado; nem há espaço imutável. Nada mais dinâmico do que o espaço por que ele vai sendo construído e destruído, permanentemente, seja pelo homem, seja pelas forças da natureza”.

Enfim, os espaços exercem influência nas pessoas, ao mesmo tempo em que as pessoas exercem influência nele. A sua organização então precisa ser intencional e direcionada para as aprendizagens das crianças e, preferencialmente, com a participação dos envolvidos.

Para finalizar, é importante ressaltar que a mediação do professor que chamamos neste artigo de mediação pedagógica não é simples interferência nas atividades dos alunos. Ela envolve planejamento intencional e escolha de mediadores potentes para o desenvolvimento do ensino. A problematização é a via principal dessa mediação pedagógica. O desenvolvimento das funções psíquicas superiores especiais nos estudantes deve ser a prioridade na relação com os conteúdos escolares.

Por isso, a atividade do professor tem como característica fundamental a intencionalidade, na medida em que ele percebe as necessidades de aprendizagens dos seus alunos e, também, visualiza as suas necessidades. O esforço de criar nos alunos novas necessidades gera nele também outras tantas, e assim, juntos vão se distanciando de visões óbvias, do tipo "isso eu já vi" e desenvolvendo o pensamento teórico e a consciência sobre o conhecimento apropriado por eles no processo de ensino e de aprendizagem.

\section{REFERÊNCIAS}

LEONTIEV, Alexis. O Desenvolvimento do Psiquismo. Lisboa/Portugal: Livros Horizonte, 1978.

LIMA, Mauymi Souza. A cidade e a criança. São Paulo: Nobel, 1989. - (coleção cidade aberta).

MELLO, Maria A. Aprendizagem Sem Dificuldades: A Perspectiva Histórico-Cultural. APRENDER Cadernos de Filosofia e Psicologia da Educação. Vitória da Conquista. Ano V, nº 9 p. 203 - 218, 2007. 
MELLO, Maria A.; CAMPOS, Douglas, A. Estudos sobre a Escola de Vigotsky: Metodologia Colaborativa de Formação Inicial e Continuada de Professores IN: ARAÚJO-FILHO, Targino de; THIOLLENT, Michel Jean-Marie. Metodologia para Projetos de Extensão: Apresentação e Discussão. Universidade Federal de São Carlos (UFSCar) - São Carlos: Cubo Multimídia, 2008, p. 293 $-304$

PETROVSKY, A. Psicologia General: Manual Didáctico para los Institutos de Pedagogía. Moscú: Editorial Progreso, 1980.

SHUARE, Marta. La Psicología Soviética Tal Como Yo La Veo. Editorial Progreso: Moscú, 1990.

SITTA, Kellen Fabiana; MELLO, Maria Aparecida. Educação Infantil, Espaços Físicos e Brincadeiras: mediadores das aprendizagens das crianças. 01. ed. Berlin: Novas Edições Acadêmicas - Ominiscriptum Markenting DEU GmbH, 2015.

VIGOTSKY, Liev S. Construção do Pensamento e da Linguagem. Martins Fontes, São Paulo, 2001.

VIGOTSKY, Liev S. Obras Escogidas. Fundamentos de Defectología. Tomo V. Madrid: Visor Distribuiciones, 1997.

VIGOTSKY, Liev S. Obras Escogidas. Psicología Infantill. Tomo IV. Madrid: Visor Distribuiciones, 1996.

VIGOTSKY, Liev S. Obras Escogidas. Problemas del Desarrollo de la Psique. Tomo III. Madrid: Visor Distribuiciones, 1995.

VIGOTSKY, Liev S. Obras Escogidas. Problemas de Psicología General. Tomo II. Madrid: Visor Distribuiciones, 1993.

VIGOTSKY, Liev S. Obras Escogidas. Problemas Teóricos y Metodológicos de la Psicología. Madrid: Visor Distribuiciones, 1991.

VIGOTSKY, Liev S. Psicología del Arte. Barcelona: Barral Editores, 1972.

Recebido em: 21 de maio de 2020. Aprovado em: 18 de junho de 2020. 